\title{
BIBLIOGRAFIA SOBRE A CULTURA SANTARÉM: HISTÓRIA E PERSPECTIVAS*
}

\author{
Denise Maria Cavalcante Gomes**
}

\section{Introdução}

Conhecida desde o século XIX, a cerâmica Santarém nunca tinha sido objeto de pesquisas sistemáticas, o que veio a ocorrer somente no final da década de 1980 , com o estabelecimento de um projeto para a área pela arqueóloga Anna Roosevelt, ainda em desenvolvimento. Antes disso, a bibliografia aponta a realização de escavações e coletas de superfície, tanto no século XIX (Barbosa Rodrigues 1875 Hartt 1885), como na década de 1920 (Nimuendajú 1949), contudo sem preocupações estratigráficas.

Entre 1939 e 1965 foram elaborados estudos estilísticos, cujas interpretações, baseadas em orientações teóricas vigentes na época e na falta de pesquisas de campo, apoiam-se em inferências sobre migrações e hipótese difusionistas (Palmatary 1939, 1960 e Corrêa 1965) para explicar o desenvolvimento cultural da Amazônia e conseqüentemente a ocorrência de estilos diferenciados como o de Santarém (Meggers e Evans 1961).

Desde então, nenhum estudo foi publicado especificamente sobre a cultura Santarém, esta que tem seu principal sítio localizado na cidade de mesmo nome, no estado do Pará. Definida como pertencente ao Estilo-Horizonte Inciso e Ponteado (Meggers e Evans 1961), sua datação é estimada, por analogia às datações de C 14 para estilos do mesmo horizonte na Venezuela, entre 1000 e 1500 AD.

Com exceção do texto contido no Catálogo da Exposição do Museu de Arqueologia e Etnologia da USP, escrito por Meneses (1972), que faz

(*) Este estudo é parte do Projeto de mestrado "Análise Iconográfica dos Vasos Cerâmicos de Santarém: a Coleção MAE-USP", desenvolvido com o apoio da FAPESP.

(**) Museu de Arqueologia e Etnologia da Universidade de São Paulo. Pós-Graduação, mestrado. referência aos trabalhos existentes sobre o tema, contextualizando-os frente às principais correntes teóricas, mas que não representa nenhum avanço no conjunto do conhecimento, um longo hiato seguiu-se sem que nada tivesse sido publicado.

Somente em 1993, a Dissertação de Mestrado de Guapindaia, que permanece na versão original, rompeu este silêncio. Seu trabalho representa o início de uma nova fase dos estudos de coleções, uma vez que estes podem incorporar os resultados das pesquisas de campo que vêm sendo desenvolvidas.

\section{I - As primeiras escavações no século XIX}

É significativo que as primeiras escavações da área tenham sido realizadas por um geólogo e um botânico, num século marcado por expedições de viajantes e naturalistas europeus ao Novo Mundo, naquele momento com objetivos científicos.

O geólogo Hartt, discípulo de Agassiz, foi o primeiro a escavar o sambaqui existente em Taperinha, localizado a $40 \mathrm{~km}$ a leste de Santarém, na margem meridional do rio Amazonas, precisamente no paranamirim de Ayayá.

Em sua expedição realizada em 1870 , Hartt foi ajudado a examinar o local pelo Sr. Rhome, proprietário em sociedade com o Barão de Santarém, da fazenda que dá nome ao sambaqui. Nesta ocasião ele chegou "um tanto levianamente à conclusão de que o depósito se formou naturalmente" (Hartt 1885), por julgar que as conchas estavam dispostas de forma muito regular e por não ter encontrado nenhụm vestígio que indicasse a ação humana.

Ao retornar à Taperinha em 1871 foi informado que o pesquisador J. B. Steere, da Universidade de Michigan, havia recuperado fragmentos de cerâmica e alguns ossos, solucionando desse modo a questão da origem do sambaqui. 
Além de conchas da espécie Hyria, Castalia e Unio, Hartt encontrou desde a superfície até 6 metros de profundidade, fragmentos de cerâmica grosseira, alguns ossos e um pedaço de carvão. A cerâmica é descrita por ele como sendo fabricada por uma argila contendo areia muito grossa, despida de ornamentação, sendo que alguns fragmentos apresentam incisões toscas.

No que diz respeito à ocupação das serras, nas imediações de Taperinha, Hartt ao se referir aos sítios dos moradores dos altos, menciona a existência de grandes áreas de terras de cor preta, cuja extensão chega a centenas de alqueires. A fertilidade do solo, segundo ele inversamente conclui, é o que garante encontrar em toda formação deste tipo, evidências de ocupação humana. ${ }^{1}$

De fato, Hartt revelou nos altos de Taperinha, a existência de fragmentos de cerâmica ornamentada e ídolos de forma humana, além de rodelas de fuso. Quando descreve a cerâmica, a impressão que se tem é a da mais completa diversidade, ao relatar a ocorrência de exemplares lustrados com argila vermelha e sem pintura, gravados com incisões geométricas, ornamentados com impressão de dedos ou asas representando animais, e finalmente com a impressão de esteira de folhas de palmeira.

Aliás, esta caracterização é estendida aos vestígios de outras localidades na área em questão, a exemplo de Panema, Itaituba, Diamantina e PaPixuna, visitadas tanto por ele, como por outros pesquisadores.

Outra informação importante fornecida por Hartt, que ajuda a reforçar a impressão de diversidade, é que nos altos de Taperinha foi desenterrada pelo Sr. Rhome, uma urna contendo restos de um esqueleto humano. Esta possuía, segundo ele, um formato de noz de carvalho, achatada em cima e um pouco estreitada abaixo do meio, com a base arredondada, abertura circular, borda elevada e feitio grosseiro, tendo a superfície alisada, sem ornamentação.

Em 1872, o botânico Barbosa Rodrigues (1875) explorou o sambaqui e a serra de Taperinha, bem

(1) Em Smith (1980) e Pabst (1991) encontramos subsídios sobre o processo de formação das terras pretas, que estão presentes em diferentes áreas da Amazônia e quase sempre associadas à existência de sítios arqueológicos. Estes autores atribuem a elas uma origem antropogênica, contrariando antigas hipóteses que consideravam as terras pretas formações naturais. como outras povoações ao longo do rio Tapajós, partindo de Alter do Chão, depois Boim, Aveiros, Pinhel, Brasília Legal, Itaituba, chegando até a região das cachoeiras. Sua intenção, conforme afirma, não era somente conhecer a vegetação, mas os costumes dos extintos Tapajós.

Embora forneça informações históricas minuciosas sobre as origens da cidade de Santarém e reconheça ser este o principal sítio onde estavam localizados os Tapajó, Barbosa Rodrigues, assim como Hartt, não menciona a ocorrência de escavações neste local.

Sobre Taperinha, baseado nos vestígios materiais e na existência de um caminho ligando o sambaqui até o cume da serra, Barbosa Rodrigues conclui que estes sítios eram habitados pelos mesmos índios. Do mesmo modo que Hartt, nota a existência das terras pretas nas chapadas das serras e atribui a escolha destas pelos antigos habitantes, por sua fertilidade e distância das enchentes.

Em Itaituba, localizada cerca de $371 \mathrm{~km}$ ao sul de Santarém, Barbosa Rodrigues encontrou fragmentos de cerâmica de dois tipos, a primeira sem ornamentação e a segunda com motivos geométricos coloridos com tinta vermelha, além de um machado de diorito compacto.

Mas é na região das cachoeiras, ao sul de Itaituba, que Barbosa Rodrigues faz sua maior descoberta. Na cachoeira de Apuhy e na do Boruré, descobriu as mesmas rochas de que eram feitos os machados, sendo que em alguns pontos julga ter visto vários sulcos nas pedras, o que indicaria o local onde estes artefatos eram polidos.

Baseado na cerâmica e também num estudo que fez de 18 machados provenientes de locais diferentes, desde Taperinha até a cachoeira do Boruré, Barbosa Rodrigues chega à conclusão que os Tapajós habitavam o baixo Tapajós, mas com o correr dos anos expandiram-se pela margem direita chegando até a cachoeira do Boruré.

A partir da evidência descoberta em Piracanã, nas proximidades de Itaituba, Barbosa Rodrigues incorre numa generalização para toda a área, dizendo que os Tapajó usavam igaçabas duplas - compostas de uma panela colocada dentro de um pote decorado com motivos geométricos - para enterrar seus mortos.

Quanto às conclusões destes primeiros estudiosos que escavaram e fizeram coletas de superfícies, desde Taperinha até Itaituba, ou mais precisamente até a cachoeira de Boruré, tanto Hartt co- 
mo Barbosa Rodrigues sugerem a ocupação dos Tapajó por toda a extensão do rio.

Do ponto de vista da pesquisa arqueológica, somente as evidências de Taperinha puderam ser interpretadas em consonância com as pesquisas que seriam mais tarde desenvolvidas por Roosevelt (1991e 1995). Sobre o domínio dos Tapajó na referida área, a julgar pelos métodos utilizados por estes pioneiros, nada garante que tais vestígios possam indicar assentamentos deste mesmo grupo.

Considerando a descrição da cerâmica, que conforme mencionado oferece uma impressão de diversidade, o material lítico e as urnas encontradas, várias hipóteses podem ser levantadas. Dentre elas, a ocupação do espaço por diferentes grupos indígenas que efetuavam trocas com os Tapajó, ou ainda o domínio de todo o território pelos Tapajó, mas com a existência de seqüências culturais diferenciadas, indicadas pelas variações de estilos cerâmicos.

Conforme tem sido dito reiteradamente por todos os pesquisadores do tema (Nimuendajú 1949, Palmatary 1960, Corrêa 1995, Guapindaia 1993), somente o desenvolvimento de pesquisas sistemáticas poderá esclarecer qualquer hipótese. Neste sentido, a comunidade acadêmica aguarda com interesse a divulgação dos resultados dos trabalhos de Anna Roosevelt.

\section{II - Nimuendajú e o impacto de suas pesquisas}

De acordo com a edição em inglês feita por Rowe, em 1952, de "Os Tapajó" de Curt Nimuendajú (1949), este último originou-se a partir dos manuscritos de 1923 e 1926, que representam as primeiras versões do texto definitivo. Redigidos em alemão, foram inicialmente relatórios feitos para o Museu de Gotemburgo, acompanhados da documentação relativa às coletas arqueológicas.

Embora contenham algumas alterações, como por exemplo o de 1926 cuja seção sobre antigos assentamentos é bem diferente na versão em português, segundo nos informa Rowe (1952), em essência tais escritos não acrescentam nada de novo ao único texto de domínio público, escrito por Nimuendajú, sobre os Tapajó.

Síntese das pesquisas arqueológicas realizadas por Nimuendajú em Santarém e arredores, entre 1923 e 1926, para o Museu de Gotemburgo, o referido trabalho contém uma caracterização cultural dos Tapajó, baseada em fontes etno-históricas, bem como informações específicas produto da observação empírica.

De modo geral, a seleção de relatos dos antigos cronistas feita por Nimuendajú - a exemplo de Acuña, Carvajal, Heriarte, Laureano de la Cruz nos informa que os Tapajó eram bastante numerosos, habitavam com certeza a foz do rio Tapajós (Santarém) e Borary (Alter do Chão), não falavam a língua Tupi mas outra diversa, eram temidos guerreiros fazendo uso de flechas envenenadas, excelentes ceramistas e que possuíam uma organização social bem diferenciada.

Quanto a este aspecto, Nimuendajú cita Heriarte que menciona a existência de um chefe comum, representando uma autoridade superior aos chefes locais de cada "rancho", constituídos por 20 a 30 famílias. Bettendorf, outro cronista citado, refere-se à existência de uma classe nobre hereditária entre os Tapajó, representada pela princesa Maria Moaçara.

Sobre os costumes religiosos e mortuários, Nimuendajú com base nas informações de Heriarte, aponta a ocorrência de práticas de endocanibalismo (ingestão de ossos triturados dos mortos misturados à bebida) e mumificação dos ancestrais, que eram reverenciados em cerimônias.

Este tipo de caracterização cultural foi utilizada em vários estudos posteriores sobre os Tapajó (Nordenskiold 1930, Palmatary 1939 e 1960, Roosevelt 1987 e 1993, e Guapindaia 1993). No entanto, acreditamos que devido à natureza parcial e fragmentária das fontes etno-históricas, sua interpretação deve ser feita associada ao registro arqueológico.

Aliás, Figueiredo (1963) num artigo em que discute a possibilidade de caracterização cultural dos Tapajó, a partir das referências presentes nos relatos etno-históricos, por outro lado nega que seja possível uma reconstituição da estrutura social do grupo, fazendo uso somente destas fontes.

Outro aspecto relevante conforme aponta Nimuendajú (1949), é o fato de que Hartt embora tenha notado a existência das terras pretas do planalto ao sul de Santarém, não chegou a reconhecer a maior e mais importante concentração de terra preta em toda a região, na cidade de Santarém, no bairro de Aldeia. Este, pode ser considerado um dos méritos de Nimuendajú.

Além disso, ele informa ter localizado entre 1923 e 1926, 65 sítios em Santarém, ao sul da ci- 
dade, na região de Alter do Chão e Samaúma, no Arapixuma, na margem sul do Lago Grande de Vila Franca e na margem direita do Amazonas, a maioria deles situados em terra firme, longe de inundações. Conclui dizendo acreditar que isto não representa nem a metade dos sítios pertencentes a esta cultura.

Nimuendajú (1949) relata ainda a existência de poços cavados pelos antigos habitantes, uma vez que os sítios do planalto ficavam longe da água corrente, bem como de caminhos ligando um depósito de terra preta a outro. Estes últimos, representavam sítios de habitação.

Embora não sejam de nosso conhecimento os documentos contendo registros sobre as coleções arqueológicas reunidas por Nimuendajú, a partir deste artigo de 1949 não se tem nenhuma pista se foram realizadas escavações estratigráficas em Santarém-Aldeia. A única referência existente, que faz crer o contrário, diz respeito à cerâmica que surge nas valas das ruas do bairro de Aldeia, após as chuvas torrenciais e que foi recolhida por ele.

Conforme pode ser observado, um considerável período separa os trabalhos de Nimuendajú da publicação do referido artigo em 1949. No entanto, foram vários os estudiosos que se propuseram a divulgar os resultados de suas pesquisas. $O$ primeiro deles foi Linné (1928), num artigo dedicado à apresentação das descobertas arqueológicas realizadas no Amapá, na Ilha Caviana e em Santarém.

Linné considera Santarém uma "civilização indígena desenvolvida" ${ }^{2}$ cuja cerâmica demonstra influências da América Central, segundo sugerido pelo próprio Nimuendajú (1949). Por outro lado, destaca o fato de que nunca foram encontradas tumbas na região e lembra as práticas de endocanibalismo existentes, reconhecendo ser audacioso afirmar que este costume reinou de forma geral.

Mesmo dizendo ser impossível determinar ao certo os limites da "civilização de Santarém", Linné menciona que Nimuendajú estima ter traçado o limite ocidental quase até Parintins, no atual estado

(2) Autores como Linné (1928), Nordenskiold (1930) e Métraux (1930), mesmo frente às poucas informações existentes e tendo como base sobretudo as evidências de cultura material, reconhecem em Santarém um grau de complexidade a ponto de identificá-la como uma "civilização" Tal qualificação é interessante pois, de acordo com as vertentes epistemológicas da época, na América, civilizações poderiam ser as dos Andes e as da Mesoamérica, mas nunca as da floresta tropical. do Amazonas, baseando-se no fato de ter encontrado grandes urnas de um estilo diferente.

Finalmente, Linné (1928) comenta algumas peculiaridades da cerâmica da bacia Amazônica. Especificamente sobre a de Santarém, destaca os vasos de bordas ocas, os de fundo perfurado como uma escumadeira - cuja função não foi estabelecida - e os de cariátides, estes últimos vistos como herdeiros de culturas centro-americanas.

Outro pesquisador que se dedicou a divulgar as descobertas de Nimuendajú foi o Barão Erland Nordenskiold. Considerado uma importante referência sobre o tema, o livro de Nordenskiold (1930) reúne informações não só sobre as pesquisas realizadas por Nimuendajú na bacia Amazônica, como também as desenvolvidas pelo próprio autor no noroeste da Bolívia, numa edição de luxo, fartamente ilustrada.

Este autor afirma literalmente que em Santarém não foi possível praticar pesquisas sistemáticas e que os achados de Nimuendajú devem-se às fortes chuvas, que cavam fossados nas ruas revelando a cerâmica. E ainda, que este pesquisador não havia encontrado uma só tumba na região.

Nordenskiold compara as descobertas arqueológicas da bacia Amazônica, identificando dois tipos de "civilizações" A primeira, caracterizada pela utilização de urnas funerárias, como as culturas Cunani, Maracá, Marajó, Caviana, Miracanguera, além daquelas nos rios Negro, Japurá e nos mounds bolivianos. E a segunda, tendo como costumes funerários o enterramento direto no solo ou a absorção estomacal dos ossos pulverizados.

Segundo este autor, os enterramentos diretos foram praticados nos mounds bolivianos, conforme observado por ele nos registros arqueológicos dos níveis mais profundos, sendo ainda o modo de se enterrar nas Antilhas. Quanto à ingestão dos ossos pulverizados, esta prática é própria de uma parte da bacia Amazônica, tendo sido identificada em Santarém, como indicam os relatos etno-históricos.

A cerâmica de Santarém, a princípio vista como completamente original, possui semelhanças apontadas por Nordenskiold com a das Antilhas e a da América Central (Chiriquí, no Panamá e Costa Rica). Dentre os traços em comum destacados por esta autor, estariam as cabeças de pássaro modeladas, encontradas nas Antilhas, além dos vasos trípodes, a representação de cariátides e os ornamentos de rãs em posição de salto, estes presentes na América Central. 
Para explicar tais semelhanças estilísticas identificadas na cerâmica pertencente a vastos territórios, Nordenskiold defende a hipótese de que ao lado de relações comerciais envolvendo esta áreas, estariam as migrações. $\mathrm{O}$ autor acredita portanto na existência de uma origem comum e aponta os Arawak - grupos encontrados desde o Grande Chaco até a costa da Flórida, na época do descobrimento - como os principais civilizadores tanto nas Antilhas como na Amazônia.

A cultura Santarém, inserida neste contexto, seria de origem Arawak ou teria sofrido fortes influências dos mesmos. Embora Nordenskiold não possua elementos para determinar a direção destas migrações, sugere que na Amazônia a evolução da cerâmica é marcada pela passagem da decoração modelada e incisa à ornamentação pintada, em grande parte devido às influências Andinas.

Quanto às ilhas mais afastadas do continente, a exemplo do Hispaniola e da Jamaica, informa que nenhuma peça com pintura feita depois da queima foi encontrada, o que implica que a migração Arawak teria ocorrido numa época antes de eles aprenderem a queimar a cerâmica pintada, quando esta era ainda muito arcaica.

Contudo, Nordenskiold enfatiza que devido às grandes distâncias e às migrações ocorridas de maneira não-simultânea, não se pode pretender que uma cerâmica do mesmo tipo encontrada em dois locais diferentes, seja da mesma época. Lembra ainda a existência das invenções locais e evoluções de estilos, o que indica a fragilidade do esquema explicativo, com base exclusivamente em comparações estilísticas e a necessidade da realização de novas pesquisas.

Outro autor que escreve sob o impacto dos trabalhos de Curt Nimuendajú é Métraux (1930), num artigo em que descreve coleções cerâmica provenientes da embocadura do rio Tefé (alto Amazonas) e da região de Manaus (médio Amazonas) pertencentes ao acervo do Museu Etnográfico de Trocadero, Paris.

Ao analisar apliques antropomorfos e zoomorfos, fragmentos de estatuetas e de vasos com detalhes modelados, além de urnas funerárias, Métraux tenta relacionar este material arqueológico às outras culturas amazônicas já conhecidas, a exemplo de Marajó e Cunani e as reveladas por Nimuendajú, em especial Santarém, buscando pensar a origem deste conjunto e sua extensão.
Métraux reafirma a hipótese de Nordenskiold, que coloca os Arawak como tribos possuidoras de uma civilização superior, sendo os vestígios arqueológicos existentes em diversas regiões da América, a leste dos Andes, atribuídos a eles.

Para Métraux, um dos principais indicadores é que se encontram tribos Arawak estabelecidas no local, ou próximas de onde foram feitas as descobertas arqueológicas, tanto na época da conquista como nas primeiras décadas deste século.

Desse modo, a cultura material de Tefé, Manaus, Marajó, Cunani, Santarém, além de determinadas regiões do Orinoco, das Guianas e Antilhas seria para este autor obra dos Arawak. Embora existam diferenças marcantes entre a cerâmica destas culturas, conclui que existe "um estilo uniforme que constitui o patrimônio de tribos de uma mesma origem étnica" (Métraux 1930: 175).

Iniciando uma outra vertente de análise, Linné (1932) num artigo sobre a cerâmica Sul-Americana, oferece informações do ponto de vista da tecnologia, baseando-se em pesquisas realizadas com peças das coleções do Museu de Gotemburgo e Riskmuseum (Stockolm) a partir do método de microemulsão, desenvolvido por Bolivar Aadlecreutz. Neste estudo, o autor trata especificamente do emprego do cariapé (cinzas de casca de árvore ricas em sílica) e do cauixí (espículas de esponjas de água doce) como aditivos misturados à argila.

De acordo com este autor, tais antiplásticos encontrados na cerâmica da Bacia Amazônica são incomparavelmente mais importantes do que outros tipos, tais como a areia ou a cerâmica triturada, pois a sílica contida no cariapé e, em maior grau nas espículas, "forma um esqueleto que aparenta, numa escala microscópica, uma cerâmica de cimento armado" (Linné 1932: 203).

Para Linné, mais do que uma necessidade, a utilização de determinado material como antiplástico, faz parte da química empírica dos índios e representa uma escolha de caráter cultural. Isto porque a distribuição geográfica destes recursos é muito maior do que a área onde de fato se identifica o seu uso.

No caso da cerâmica de Santarém, conforme aponta Linné (1932), o antiplástico empregado é o cauixí, cujas espículas pertencem à espécie de água doce denominada Parmula batesii. Devido às características de maleabilidade e maciez das espículas, o resultado geral é uma cerâmica de alto grau de dureza, mas ao mesmo tempo leve. 
Comparando a área de distribuição geográfica dos grupos da América do Sul, que empregam cauixí e cariapé na fabricação da cerâmica, Linné constata que ambos os métodos foram utilizados numa época antiga no Baixo Amazonas, conforme atesta o exame das peças arqueológicas.

Finalmente, conclui que esta região pode indicar o local de origem destas descobertas relativas à tecnologia cerâmica. Tais técnicas estariam associadas aos Arawak, vistos por Linné como responsáveis pela propagação das mesmas a outras regiões da Bacia Amazônica e seus afluentes, além das Guianas.

É interessante notar que os trabalhos escritos a partir das pesquisas realizadas por Nimuendajú no Baixo Amazonas e particularmente em Santarém (Linné 1928 e 1932, Nordenskiold 1930, Nimuendajú 1949) constituem um todo coeso.

Talvez isto ocorra porque as mesmas fontes escritas e materiais (coleções) sejam partilhadas pelos autores. E ainda, pelo fato de estes concordarem com a hipótese sobre a origem da cultura Santarém estar relacionada ao "processo civilizatório" empreendido pelos Arawak nas Américas.

\section{III - Estudos de coleções: abordagens descritivas e difusionistas}

Palmatary inaugura os estudos de coleções com seu primeiro trabalho de 1939. A análise da autora é feita a partir dos acervos do Museu da Universidade da Pensilvânia, Filadelfia; do Museu do Índio Americano, Heye Foundation, em Nova York; da Universidade Católica da América, em Washingthon e finalmente do Museu Etnográfico de Gotemburgo, Suécia.

A primeira abordagem da análise é uma tentativa de organização tipológica dos vasos, divididos inicialmente em grandes vasos e pequenos vasos. De acordo com a autora, os grandes vasos podem ser de 8 tipos com subdivisões: tipo 1 jarros de efige (masculinos e femininos); tipo 2 cariátides, verdadeiras e falsas; tipo 3 vasos com base anelar alargada; tipo 4 pratos concêntricos; tipo 5 vasos de base redonda; tipo 6 vasos de base plana; tipo 7 vasos trípodes; tipo 8 vasos de base cônica.

Assim como os grandes vasos, os pequenos estão dividos em outros 8 tipos, cujo principal traço diagnóstico é também o formato da base. A escolha deste critério de classificação não é justi- ficada por Palmatary, mas sem dúvida constitui um problema, pois num mesmo tipo podem estar, e freqüentemente estão, reunidas formas completamente díspares. $O$ tipo 2 pertencente aos grandes vasos é um exemplo, ao agrupar tanto as verdadeiras cariátides, quanto os vasos de gargalo que possuem bases iguais, mas no entanto constituem formas completamente diferentes.

Em seguida, Palmatary descreve os elementos decorativos observando a ocorrência de decoração incisa, em baixo relevo, alto relevo e figuras modeladas. Outros traços observados são o formato e decoração da borda, alças, suportes, pés e bases, ainda a ocorrência de estatuetas antropomorfas, de figuras semi-humanas e as representações zoomorfas presentes na cerâmica.

A fim de fornecer substrato para uma discussão lógica sobre as correlações estilísticas observadas, Palmatary comenta as crônicas de expedições européias da época do contato, que relatam a exemplo de Carvajal, rotas que vão desde os Andes até a foz do Amazonas e dirigem-se para as Antilhas. Após ter examinado as possibilidades da viagem de Carvajal (séc. XVI) com um especialista da Canadian National Lines, a autora conclui que o relato parece não só verossímil como nem tão difícil de ser efetuado.

Com isso, reconhece ser plausível a existência de rotas ligando Santarém e o Caribe, uma vez que o rio Negro, tributário do Amazonas, representa uma conexão direta com o rio Orinoco, via canal de Casiquiare. A partir da bacia do rio Orinoco, conclui que seria possível atingir o Caribe.

Este raciocínio sustenta a elaboração de inferências de possíveis correlações entre o Médio Amazonas e certas culturas ao norte, localizadas principalmente na Guiana Inglesa, na Venezuela, no Panamá, na Costa Rica, nas Antilhas e em algumas áreas dos mounds no sul dos Estados Unidos.

Palmatary (1939) elege traços estilísticos e estruturais presentes na cerâmica de Santarém (formato dos olhos, da base e dos suportes), formas típicas (cariátides, pratos concêntricos, vasos de gargalo) além de motivos iconográficos (bicefalia e padrões geométricos) e os descreve associandoos a outras áreas. No quadro de correlações organizado pela autora, os locais de maior ocorrência de traços em comum com Santarém são o Vale do Mississipi (10 traços freqüentes) e em seguida, a área do Istmo (6 traços frequientes). 
Embora a autora oscile entre a mais franca especulação e a escolha de uma posição mais cautelosa, apoiando-se nas afirmações de outros autores como Nordenskiold e Linné, ou ainda dialogando com hipóteses contrárias, concluímos que para ela "os mounds estão ligados ao Amazonas, por intermédio da área do Istimo" (Palmatary 1939). Por fim, afirma que a cultura Tapajônica representa uma cultura composta, contendo traços de tradições da América do Sul, mas também com elementos do norte que foram difundidos, a exemplo das figuras de base crescente, cariátides, garrafas, bicefalia etc..

Kroeber (1942) num artigo sobre este estudo, realiza uma análise estatística a partir da lista de correlações estilísticas tabulada por Palmatary e procura refletir sobre os resultados apresentados. Ele identifica 2 grupos ou possibilidades de conexão com Santarém: (1) Grandes Antilhas e Pequenas Antilhas; (2) Vale do Mississipi, área do Istmo e Venezuela. $\mathrm{O}$ sul dos Estados Unidos coloca-se então como área intermediária entre os dois. A filiação de Santarém, embora não apresente grande freqüência, refere-se ao grupo 2 . O grupo antilhano embora esperado, coloca-se como um segundo grupo.

Para Kroeber (1942), de acordo com a análise estatística, pode-se concluir que existem algumas relações unindo uma vasta área desde o Médio Mississipi até o Baixo Amazonas e que, de maneira distinta, existe um desenvolvimento antilhano que influenciou a Flórida e outros estados ao sul, mas não num alto grau como as influências do Amazonas-Istmo e Mississipi que penetraram no sudoeste. As relações entre o norte da América do Sul e as Antilhas parecem surpreendentemente tênues, tendo em vista o fato que os Arawak e os Carib estavam estabelecidos em ambas as áreas.

Quanto ao leste dos Estados Unidos, Kroeber (1942) afirma que esta cultura como um todo foi basicamente influenciada pelo México, mas nas proximidades da Flórida também pelas transmissões antilhanas, o que pode indicar uma chave para compreender as influências sul americanas na cultura nativa dos Estados Unidos, e que dependeriam de futuras pesquisas.

Kroeber aponta a fragilidade do esquema e conclui que não se deve fazer muitas inferências a partir destas indicações, uma vez que a lista que serviu de base para estes cálculos baseia-se somente na cerâmica e que os traços diagnósticos foram selecionados a partir do ângulo de Santarém. No que se refere às áreas comparadas, muitas são pouco definidas, sendo que o México deveria ter sido incluído no estudo. Finalmente, para Kroeber, a amostra talvez sirva para indicar o quão amplas tais correlações podem resultar.

A segunda e mais conhecida publicação de Palmatary (1960) sobre o tema inclui a análise das coleções anteriormente estudadas e mais as do $\mathrm{Mu}$ seu Paraense Emílio Goeldi; do Museu do Estado, no Recife; do Museu Nacional, no Rio de Janeiro; da Fundação Brasil Central; além de coleções particulares pertencentes a Frederico Barata; a Carlos Estevão de Oliveira; ao Sr. Charles H.T. Townsed e ao Sr. Carlos Liebold.

Como nesta época o conhecimento arqueológico da região não tinha sido alterado, sendo que Nimuendajú permanecia ainda como a última referência quanto à realização de trabalhos de campo, Palmatary mantém a mesma fórmula do trabalho anterior. A única novidade, que precede a análise estilística, são notas contendo informações geográficas e históricas, estas últimas baseadas nos relatos etno-históricos, tendo por objetivo realizar uma caracterização cultural dos Tapajó.

$\mathrm{Na}$ análise tipológica e estilística desenvolvida pela autora, o formato da base ainda é o traço diagnóstico mais preponderante, sendo observado novamente o mesmo problema ao reunir segundo certas categorias, formas e tratamentos decorativos completamente diferentes. Vinte e cinco tipos foram criados para descrever formas inteiras, fragmentos destacados e traços estilísticos. Outro aspecto observado é que, de modo geral, a descrição das peças é feita de maneira um tanto subjetiva, sem a utilização de termos técnicos.

Um outro quadro de correlações é elaborado, na tentativa de estimar a distribuição de traços comuns à cerâmica Santarém, cobrindo uma vasta área arqueológica desde o sul dos Estados Unidos até a Argentina. A conclusão de Palmatary (1960) a partir dos elementos apresentados, recai sobre a antiga hipótese da existência de uma ligação entre a cultura Santarém e o sul dos Estados Unidos. Entretanto, os dados não são discutidos com objetividade, o que resulta num sumário de considerações gerais acerca de particularidades estilísticas e inferências sobre rotas de comércio e migrações.

Meggers (1960), com a autoridade de quem naquela época estava profundamente envolvida com a arqueologia brasileira, escreve uma resenha 
sobre o livro de Palmatary criticando-o do começo ao fim. Sobre o título "The Archaeology of the Lower Tapajós Valley" Meggers sugere a substituição do termo arqueologia por cerâmica, uma vez que a autora nada contribui para o conhecimento arqueológico da região, seja informando sobre os sítios e sua estratigrafia ou fazendo uso das modernas técnicas de descrição da cerâmica.

Este último aspecto parece incomodar a autora pois o método Ford decididamente não fazia parte do enfoque de Palmatary.

Quanto à metodologia de classificação de Palmatary, Meggers ironiza dizendo que os dados são apresentados de maneira "única", tendo como principal critério a forma da base cujas implicações são aquelas já mencionadas, ao reunir num mesmo tipo formas, acabamentos de superfície e decoração diversificados. $\mathrm{O}$ resultado disso, segundo Merggers, é a dificuldade de se chegar a uma compreensão global do complexo cerâmico, do ponto de vista arqueológico.

Ao abordar o quadro de correlações elaborado por Palmatary, Meggers critica a escolha dos elementos diagnósticos e os locais correlacionados, "cujo grau de especificidade varia desde a Ilha de Marajó, a costa oeste Sul Americana até o Vale do Mississipi" (Meggers 1960: 1105). Para Meggers, pouco significado pode ser dado a estas correlações, pois tanto no caso de Marajó quanto do Vale do Mississipi, não existe nenhum esforço da autora para determinar se os traços estilísticos correlacionados pertencem ao mesmo período.

Sobre a escolha de traços diagnósticos, Meggers conclui que se a autora tivesse dado maior atenção a elementos característicos da cerâmica Santarém, como a incisão e a modelagem, certamente Palmatary teria chegado a conclusões diferentes, provavelmente enfatizando semelhanças existentes com o noroeste da América do Sul.

Contudo, mesmo frente às críticas procedentes de Meggers, Palmatary $(1960)^{3}$ permanece ainda hoje como uma das referências obrigatórias sobre a cultura Santarém. Tanto a tipologia como as descrições dos artefatos, acompanhadas de fotos, cons-

(3) Trabalhos como os de Easby (1952) e Collier (1989), seja pelo tratamento descritivo do primeiro, ou pela utilização dos relatos de fontes etno-históricas refentes aos Tapajó no segundo, possuem nitidamente como parâmetro os estudos anteriores realizados por Palmatary. tituem ponto de partida para todo estudioso do tema, principalmente devido à ausência de publicações.

Representando uma outra vertente dos estudos de coleções, Frederico Barata (1950, 1951, 1953a, 1953b, 1954) publica uma série de artigos na década de 50, a maioria deles sobre a cerâmica de Santarém, cuja abordagem tem como ênfase o aspecto artístico. Desse modo, nas análises estilísticas produzidas pelo autor estão ausentes os paralelos com outras culturas, bem como os questionamentos sobre a origem e filiações do estilo em questão.

Além de informações interessantes sobre as escavações desenvolvidas pelo próprio autor e dos achados provenientes dos quintais no bairro de Aldeia, os estudos de Barata oferecem uma descrição minuciosa das formas típicas de Santarém, bem como observam o processo de crescente estilização da cerâmica. Quanto a este último aspecto, as fontes do autor são as reflexões de F. Ward sobre os desenvolvimentos da forma, a partir da cerâmica da Costa Rica e de William Holmes sobre a cerâmica de Chiriqui. Mas segundo Barata (1950) é de Franz Boas que provém sua principal inspiração.

De fato, encontramos em Barata um leitor fiel às concepções de Boas sobre arte primitiva. Daí resultam as interpretações sobre as "séries evolutivas", percebidas por ele através de um estudo comparativo de elementos zoomorfos, pertencentes aos vasos de cariátides, que gradativamente chegam a representações antropomorfas (Barata 1950). Mas o que nos parece uma aplicação original das categorias boasianas, é a identificação de elementos zoomorfos presentes nos padrões geométricos, tornando possível o reconhecimento do motivo da rã, da cobra, da coruja, da tartaruga e da onça (Barata 1953a).

A última publicação conhecida, que trata especificamente da cultura Santarém, é o estudo de Corrêa (1965) sobre as estatuetas de cerâmica Santarém. Neste trabalho, a autora analisa 119 exemplares, pertencentes ao acervo do Museu Paraense Emílio Goeldi, observando técnicas de manufatura, decoração, acabamento de superfície, dimensões e estilo. Corrêa propõe, ainda, uma classificação diferente daquela apresentada por Palmatary (1960).

Segundo Corrêa, o principal problema identificado na tipologia elaborada por Palmatary é que esta reúne num só tipo as estatuetas antropomorfas, de base crescente, estatuetas de pedestal, fragmen- 
tos de estatuetas antropomorfas, estatuetas zoomorfas, fragmentos de estatuetas zoomorfas e as estatuetas antropo-zoomorfas.

Para Corrêa, o mais lógico parece separá-las em antropomorfas e zoomorfas. As antropomorfas são então subdivididas segundo a base (semi-lunar, unípede, circular e de pedestal) e em seguida, segundo a postura (ereta, acocorada e sentada). Levando em conta o pequeno número de exemplares existentes na amostra estudada, de estatuetas zoomorfas e antropo-zoomorfas, a autora cria as categorias zoomorfas e inclassificadas.

Frente aos resultados obtidos (estatuetas antropomorfas $97 \%$; estatuetas femininas $34 \%$; e estatuetas antropomorfas de base semi-lunar $67,2 \%$ ) a autora chama atenção para a falta de pesquisas estratigráficas e de seriação na área, o que impossibilita situar o material cronologicamente.

De acordo com o exposto na introdução do trabalho, Corrêa (1965) tem como referencial teórico os quatro Estilo-Horizontes estabelecidos por Meggers e Evans (1961). A cultura Santarém, incluída no Estilo-Horizonte Inciso e Ponteado, tem sua posição cronológica, baseada em datações de C-14 na Venezuela, calculada entre 1000 e 1500 $\mathrm{AD}$. Além disso, sobressaem as idéias de antigos contatos culturais e migrações, cujos deslocamentos humanos teriam utilizado o sistema fluvial amazônico e seus tributários.

\section{IV - O Projeto Baixo Amazonas}

Desde fins da década de 80, a arqueóloga Anna Roosevelt vem trabalhando na região de Santarém, num projeto que objetiva estabelecer as seqüências do desenvolvimento cultural da área. Com uma metodologia que combina pesquisa de arquivos, estudos de coleções e escavação estratigráfica, além do uso de diferentes métodos de datação dos artefatos, Roosevelt desenvolveu uma sequiência hipotética e foi a campo para testá-la. Esta era composta das seguintes fases: Santarém, Igarapé-Açu, Aldeia, Lago Grande, Taperinha, Ayaya e Rhome (Guapindaia 1993).

A fase Santarém, mais recente (cerca de 1000 anos), estaria associada às formações sociais complexas descritas como cacicados ou chefias (Roosevelt 1987, 1989, 1991), sendo que a partir das informações das fontes etno-históricas estima-se que teriam grandes assentamentos populacionais ba- seados na agricultura, coleta, comércio e tributo. A cerâmica da chamada cultura Santarém, constituída de vasos elaborados e estatuetas, estaria, portanto, identificada a esta fase.

$O$ resultado das pesquisas a fim de confirmar a hipótese quanto a existência de cacicado ou chefia em Santarém, ainda não foi divulgado. Entretanto, Roosevelt (1996) apresentou evidências que apontam o povoamento na Amazônia durante o Pleistoceno (11.200 A.P.) ao escavar a Caverna da Pedra Pintada, em Monte Alegre. A presença humana foi estabelecida por vários artefatos líticos, bifaciais e unifaciais, além de vestígios biológicos, apontando a existência de uma cultura distinta, contemporânea da cultura Clóvis, da América do Norte, e plenamente adaptada ao meio-ambiente tropical.

Conseqüentemente, Roosevelt (1995) e Roosevelt et alii $(1991,1996)$ enfatiza que o meioambiente tropical não pode ser mais visto como barreira ecológica para o antigo povoamento na Amazônia e nem como fator de decadência de culturas complexas. No que tange às ocupações cerâmicas, tanto na Caverna da Pedra Pintada como em Taperinha, Roosevelt (1995) e Roosevelt et alii (1996) encontrou vestígios, cujas datações radiocarbônicas e por termoluminescência situam a cerâmica do Baixo Amazonas no oitavo milênio A.P. e, portanto, como a mais antiga das Américas.

Segundo Roosevelt (1995) e Roosevelt et alii (1991) tais evidências demonstram que a cerâmica dos complexos de Taperinha e da Pedra Pintada seriam entre 1.000 e 1.500 anos mais antigas do que aquelas do norte da América do Sul e 3.500 anos mais antigas do que as sequiências estabelecidas nos Andes Centrais e na Mesoamérica. Com isso, a hipóteses de que as tradições cerâmicas da Amazônia teriam derivado destas áreas por difusão cultural ou migração, cairiam por terra. Roosevelt (1995) conclui: "Isto não quer dizer, entretanto, que a Amazônia foi o centro da cerâmica no Novo Mundo. As diferenças distintivas na cerâmica de região para região sugerem que devem ter existido vários centros"

\section{V - Novas perspectivas para os estudos de coleções}

Conforme referido, o último estudo publicado que trata especificamente da cultura Santarém é o de Corrêa (1965). Depois disso, encontramos a 
Dissertação de Mestrado de Vera Lúcia Calandrini Guapindaia, que data de 1993. Entitulado "Fontes Históricas e Arqueológicas sobre os Tapajó", o trabalho tem por objetivo caracterizar culturalmente os Tapajó. Para tanto, a autora analisou a coleção Frederico Barata, do Museu Paraense Emílio Goeldi, dando ênfase ao aspecto tecnológico da cerâmi$\mathrm{ca}, \mathrm{e}$ reuniu fontes escritas de natureza histórica $\mathrm{e}$ arqueológica.

Ao lado da caracterização cultural dos Tapajó, baseada na leitura dos relatos etno-históricos, a contribuição de Guapindaia (1993) reside no desenvolvimento de um perfil tecnológico da coleção, a partir do exame da matéria prima, dos instrumentos utilizados e das técnicas de manufatura da cerâmica. A análise tecnológica revelou dados que se chocam com certas generalizações presentes na literatura sobre o tema, indicando a necessidade de pesquisas neste sentido.

Um dos exemplos é a utilização do cauixí, considerado o antiplástico característico da cerâmica de Santarém (Linné 1932, Meggers e Evans 1961). Guapindaia (1993) aponta a ocorrência de aditivos de origem mineral (rocha triturada, grãos de quartzo e areia), animal (cauixí) e vegetal (cariapé), além de caco de cerâmica moído. Segundo ela, o aditivo mais usado foi a mistura de cauixí e caco moído em $54,27 \%$ dos artefatos analisados.

As conclusões da autora conduziram à percepção de dois grupos cerâmicos distintos. $O$ primeiro, considerado da época do contato, inclui objetos confeccionados com o uso de torno e cachimbos angulares, decorados com motivos de representação da flora. O segundo - sem influência européia - subdivide-se no grupo tipicamente Tapajônico e no grupo classificado como de influência Tapajó, que apresenta diferenças quanto à manufatura, técnicas de acabamento e decoração. Este segundo subgrupo levou Guapindaia (1993) a levantar 3 possibilidades: os artefatos pertenciam aos Tapajó, só que eram de uso utilitário; ou pertenciam a grupos que conviveram com os Tapajó na área; ou a um grupo mais antigo.

Vale observar que para melhor compreender as diferenças presentes na cerâmica, Guapindaia utilizou-se - com a devida autorização - das informações contidas no projeto e no relatório de pesquisa produzidos por Roosevelt. Com isso, o trabalho de Guapindaia marca uma nova etapa dos estu- dos de coleções, que abandonam o terreno das inferências e passam a dialogar mais de perto com os dados revelados pelo registro arqueológico.

\section{Conclusões}

O exame da bibliografia sobre a cultura Santarém, de acordo com uma perspectiva histórica, revela a existência de quatro momentos diferenciados. O primeiro, marcado pelas pesquisas dos pioneiros do século XIX, que consideram os vestígios encontrados por toda a extensão do rio Tapajós como pertencentes a um mesmo grupo indígena. Em segundo lugar, vêm as escavações realizadas por Nimuendajú propiciando o surgimento de trabalhos (Linné 1928, Nordenskiold 1930, Métraux 1930) que relacionam a cultura Santarém ao "processo civilizatório dos Arawak".

Um terceiro momento, pode ser identificado com os estudos de coleções de abordagem artística (Barata 1950, 1951, 1953a, 1953b) e arqueológica (Palmatary 1939 e 1960, Corrêa 1965). Estes últimos, baseados nos pressupostos teóricos vigentes na época, ou ainda devido a ausência de escavações, além de serem descritivos partilham de explicações difusionistas e de possíveis correntes migratórias ligando Santarém a outras áreas da América.

Finalmente um quarto momento, representado pelas pesquisas de campo e pela bibliografia produzida por Roosevelt, cujas hipóteses postulam a existência de uma longa seqüência de ocupação pré-histórica na Amazônia, culminando com as sociedades complexas e hierarquizadas, que foram desarticuladas pelos colonizadores. Deste momento, fazem parte ainda os estudos de coleções que podem se beneficiar das novas fontes de informações existentes.

\section{Agradecimentos}

A Vera Lúcia Guapindaia, pesquisadora do Museu Paraense Emílio Goeldi, pelas indicações bibliográficas; a Eleuza Gouveia, bibliotecária, e Vera Maia da Silva, auxiliar de biblioteca, pelo empenho pessoal em localizar referências não existentes na biblioteca do MAE-USP. 


\section{Referências Bibliográficas}

ALBERTO TORRES, $\mathrm{H}$.

1940 Arte Indígena da Amazônia. Revista do Patrimônio Histórico e Artístico e Nacional, v. 6, Rio de Janeiro: 1-15.

BARATA, F.

1944 Os maravilhosos cachimbos de Santarém. Estudos Brasileiros, v.13, Rio de Janeiro: 270293.

1950 A arte oleira dos Tapajó. I: Considerações sobre a cerâmica e dois tipos de vasos característicos. Publicações do Instituto de Antropologia e Etnologia do Pará, 2, Belém. 47p.

1951 A arte oleira dos Tapajo. II: Os cachimbos de Santarém. Revista do Museu Paulista, 5, São Paulo: 183-198

1953a Uma análise estilística da cerâmica de Santarém. Cultura, ano II, 5: 185-205, RJ.

1953b A arte oleira dos Tapajó. III: Alguns elementos para a tipologia de Santarém. Publicações do Instituto de Antropologia e Etnologia do Pará, 6, Belém. $16 \mathrm{p}$.

1954 O muiraquitã e as contas dos Tapajó. Revista do Museu Paulista, 8, São Paulo: 229-259.

1968 As Artes Plásticas no Brasil: Arqueologia. Rio de Janeiro, Edições de Ouro.

BARATA, $M$.

1948 Algumas notas sobre a Cerâmica de Santarém (Brasil). Actas del XXVIII Congrès International des Americanistes, Paris: 649-650.

BARBOSA RODRIGUES, J.

1875 Exploração e Estudo do Valle do Amazonas. O Rio Tapajós. Rio de Janeiro, Tipographia Nacional.

COLLIER, $\mathrm{M}$.

1989 Tapajós: A Summary of their culture at the time of contact. Ms. Dissertation, George Washington University.

CORRÊA, C.G.

1965 Estatuetas de cerâmica na cultura Santarém. Publicações avulsas. Museu Paraense Emilio Goeldi, 4, Belém: 88 p.

1971 Cerâmica de Santarém. Antologia da Cultura Amazônica,v. 6, São Paulo: 73-77.

1973 A Cerâmica Arqueológica de Santarém. Revista da Festa de Nossa Senhora da Conceição, Santarém: 27-29.

CRULS, G.

1942 Arqueologia Amazônica. Revista do Serviço do PatrimônioHistórico e Artístico Nacional, 6, Rio de Janeiro: 169-220.

EASBY, E.K

1952 The Pre-Conquest Art of Santarém, Brazil. Ms. Dissertation, Faculty of Philosophy, Columbia University.

\section{FIGUEIREDO, $\mathbf{N}$.}

1954 Arte Amazônica. Habitat: revista das artes no Brasil, 15, São Paulo: 41-45.
1963 Os Problemas de uma Abordagem Estrutural em Sociedades Indígenas Extintas na Amazônia - Os Tapajó. Revista de Educação e Letras, $I$, (2), Universidade Federal do Pará, Imprensa Universitária: 149-156.

GUAPINDAIA, V.L.C.

1993 Fontes Históricas e Arqueológicas sobre os Tapajó: A Coleção Frederico Barata do Museu Paraense Emilio Goeldi, Dissertação de Mestrado, Universidade Federal de Pernambuco, Recife.

HARTT, C. F.

1885 Contribuição para a Ethnologia do Valle do Amazonas. Archivos do Museu Nacional, VI: 1-174.

KROEBER, A. L.

1941/42 Tapajo Pottery. American Antiquity, 7: 403-405. LINNÉ, S.

1928 Les Recherches Archéologiques de Nimuendajú au Brésil. Journal de La Societé des Americanistes de Paris, T. XX: 71-91.

1932 Contribution a L'Etude de la Ceramique Sudamericaine. Revista del Instituto de Etnologia, VII, Tucuman: 199-232.

MASON, J.A.

1948 New Pottery types from Santarem, Brazil. Trabajos Cientificos del XXVII Congresso Internacional de Americanistas (Sevilla 1935), I, Madrid: 55-69.

MEGGERS, $\mathrm{B}$.

1960 Review of the Archaeology of the Lower Tapajos Valley, Brazil. American Anthropologist, 62: 1104-1105.

MEGGERS, B.; CLIFFORD E.

1961 An Experimental Formulation of Horizon Styles in the Tropical Forest of South America. S. Lothrop (Ed.) Essays in Pre-Columbian Art and Archaeology. Cambridge, Mass, Harvard University Press: 372-388.

MENESES, U.T.B. de

1972 Arqueologia Amazônica (Santarém). Museu de Arqueologia e Etnologia, São Paulo.

MÉTRAUX, A.

1930 Contribution à l'Etude de l'Archéologie du Cours Supérieur et Moyen de l'Amazone. Revista del Museu de La Plata, XXXII: 145-185.

NIMUENDAJÚ, C.

1949 Os Tapajó. Boletim do Museu Emilio Goeldi, X, Belém: 93-106.

1952 The Tapajo. J. H. Rowe (Ed.) Kroeber Anthropological Soc. Papers, 6 Berckley: 1-26.

OLIVEIRA, C.E.

1939 A Cerâmica de Santarém. Revista do Serviço do Patrimônio Histórico e Artístico Nacional, 3, Rio de Janeiro: 7-33.

PABST, E.

1991 Critérios de distinção entre terra preta e latossolo na região de Belterra e os seus significa- 
dos para a discussão pedogenética. Boletim do Museu Paraense Emilio Goeldi, NS, Antropologia, 7 (1): 5-19.

PALMATARY, H.C.

1939 Tapajo Pottery. Etnologiska Studier, 8, Gotemburgo: 1-136.

1960 The Archaeology of the Lower Tapajós Valley - Brazil. Transactions of the American PhiloROOSEVELT, A.C. sophical Society, New Series, 50: 243 p.

1987 Chiefdoms in the Amazon and Orinoco. R. Drennan; C. Uribe (Eds.) Chiefdoms in the Americas. Lanham, University Presses of America: 153-185.

1993 The Rise and Fall of the Amazonian Chiefdoms. L'Homme, 126-128, XXXIII, (2-4): 255-282.

1995 Early Pottery in the Amazon. Twenty Years of Scholarly Obscurity. W. K. Barnet; J. Hoopes (Eds.) The Emergence of Pottery. Technology and Innovation in Ancient Societies. Washington, Smithsonian Institution Press: 115-131.

ROOSEVELT, A.C.; HOUSLEY, R.A.; IMAZIO DA SILVEIRA, M.; MARANCA, S.; JOHNSON, R.

1991 Eighth Millennium Pottery from a Prehistoric Shell Midden in the Brazilian Amazon. Science, 254: 1621-1624.

Recebido para publicação em 29 de julho de 1997.
ROOSEVELT, A.C.; LIMA DA COSTA, M.; LOPES MACHADO, C.; MICHAB, M.; MERCIER, N.; VALLADAS, H.; FEATHERS, J.; BARNETT, W.; IMAZIO DA SILVEIRA, M.; HENDERSON, A.; SLIVA, J.; CHERNOFF, B.; REESE, D.S.; HOLMAN, J.A.; TOTH, N.; SCHICK, K.

1996 Paleoindian Cave Dwellers in the Amazon: The Peopling of Americas. Science, 272: 372-384.

\section{ROSSANI, A.B.}

1938 Algo sobre ceramica Tapajoara. Revista Geografica Americana, 9, ano 5, (56) Buenos Aires: 319-323.

SCATAMACCHIA, M.C.M.; DEMARTINI, C.M.C.; BUSTAMANTE, $A$.

1996 O aproveitamento Científico de Coleções Arqueológicas: A Coleção Tapajônica do MAEUSP. Revista do Museu de Arqueologia e Etnologia, São Paulo, 6: 317-333.

SERRANO, A

1939 Cerâmica de Santarém. Revista Geografica Americana, 9, ano 5, (54) Buenos Aires: 197-203.

SMITH, N.

1980 Anthrosols and Human carrying capacity in Amazonia. Annals of the Association of American Geographers, 70 (4): 553-566. 